------Jou. Raf. Sci., Vol. 20, No.4 pp 38- 51, 2009------

\title{
The Effect of the Chain Sequence Distribution, Nature of Monomers and Temperature on the Electrical Conductivity of some Unsaturated Amide-Ester Copolymers
}

\author{
Asaad F. Khattab
}

\author{
Sa'ad F. Mahmood \\ Department of Chemistry \\ College of Science \\ Mosul University
}

\author{
Yousif A. Shahab
}

(Received 14 / 4 / 2009 ; Accepted 15 / 6 / 2009)

\begin{abstract}
Ten Amide-ester copolymers were synthesized, whereby the sequence distribution and the used dicarboxylic acids were varied. The electric conductivity of the copolymers are determined in the pure and doped states. The results showed that two factors are important in determining the conductivity levels: the flexibility of the polymer chains, and the efficiency of conjugation along the chains. Thus acidic units that give rise to coiled chains structure, and hence flexibile segments gives high conductivity compared with acid units that give rise to extended structure and rigid segments like terephthalic acid. The introduction of saturated units that interrupts the chains conjugation decrease the electrical conductivity of the polymers.

The temperature dependence of the electrical conductivity $(\sigma)$ of the investigated copolymers was studied in the temperature range (303-373K). A plot of $\ln (\sigma)$ versus $(1 / \mathrm{T})$ reveals that two regions with an inflection point at the glass transition temperature Tg of the polymers. The Tg of the investigated polymers determined by this method was found to be influenced by the nature of the repeating unit of the polymers and their sequence distribution.

Keywords: Amide-ester copolymers, electrical conductivity, sequence distribution, monomers nature, glass transition temperature .
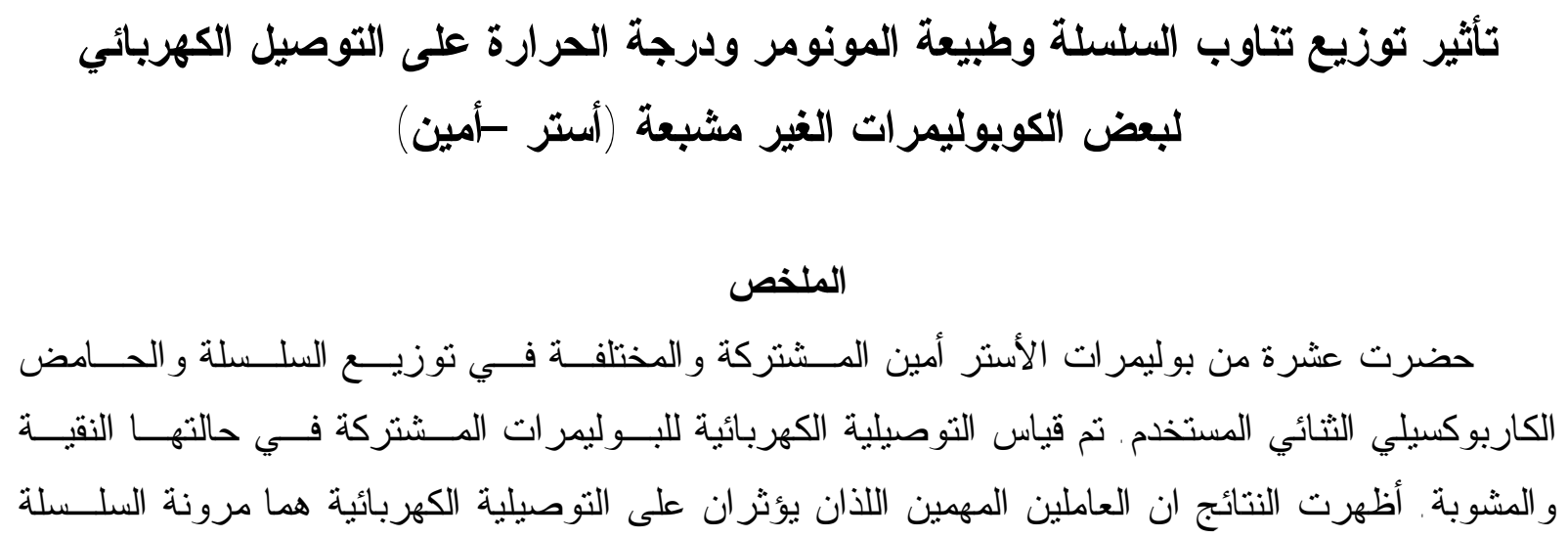


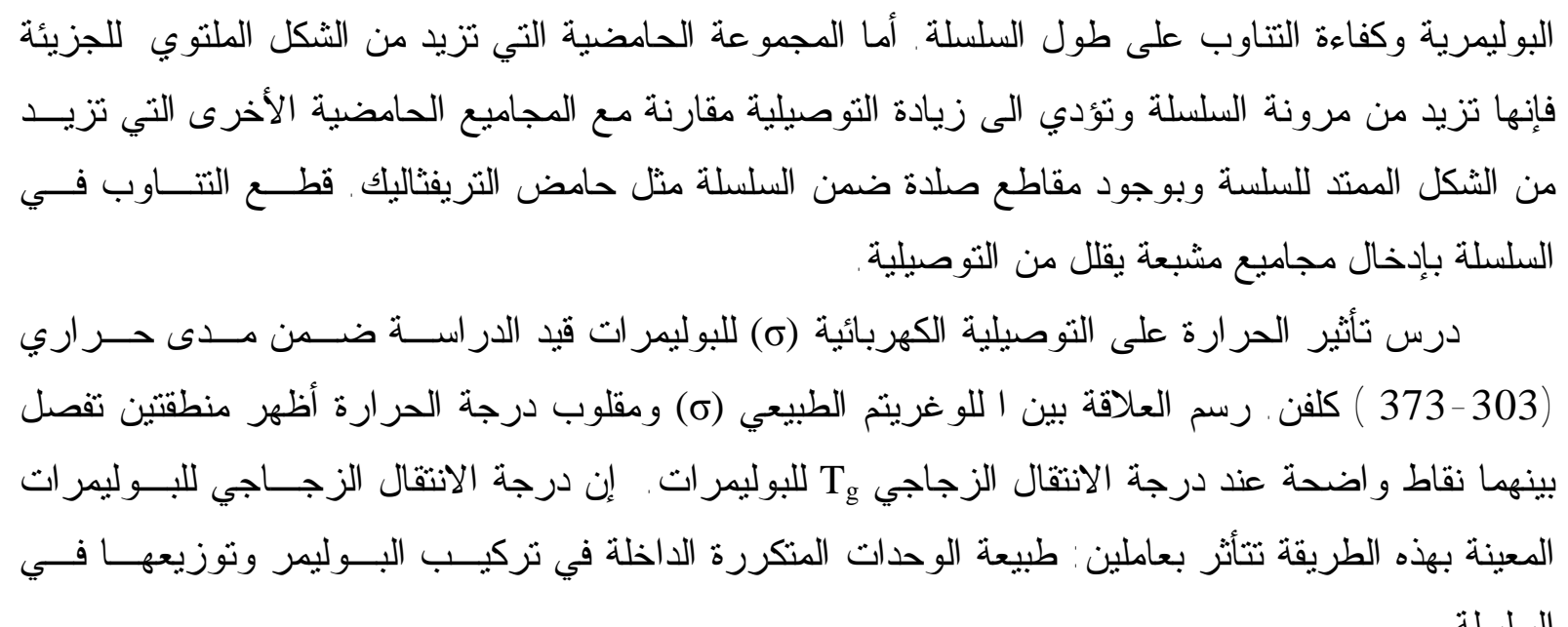

\section{INTRODUCTION}

Many authors studied the effect of molecular structure of monomers upon the electrical conductivity of the polymer. The results indicate that there are two main factors influencing the extent of electrical conductivity of conjugated polymers in their pure and doped states: (Blythe,1979; Wegner,1981 and AL-Shawabkeh et al., 2007 )The efficiency of conjugation transmission through the whole polymeric chain, and the flexibility of the polymeric chain. The former factor originates from the decrease in the electronic energy band gap between HOMO and LUMO (Keith ,1978).

According to Boltzman distribution Law, the population of electrons in the excited state will increase with a decreased energy band gap. Hence more electrons will have the possibility of participitation in the process of charge and electrical conduction. The effect of the chains flexibility on the electrical conductivity arises from the inter-chain collusions which make the direct transfer of electrons among the chains possible without a need for a jump through space that requires overcoming of the potential barriers with relatively high activation energies. It is conceivable that linking conjugated macromolecular blocks with non-conjugated flexible molecular chains would provide polymeric systems .( Yang and Yang, 1994) with improved conductive properties.

The segmental motion of the polymeric chains provides a reasonable explanation for the temperature dependence of the conductivity of conjugated polymers. The conductivity process is affected through transport of charge carries which traverse through the space separating the chains. Shahab and coworkers(AL-Shawabkeh et al., 2007) pointed out that the inter-chain charge carriers transfer is a function of the strength of electronic donoracceptor interaction between the exchainging chains moeities. This transfer is further facilated by the chains collosions and the external electric field.

In the present work ten Amide-ester copolymers differing in their monomer units and in their sequence distribution are synthesized in order to study the influence of monomer sequence distribution, the nature of the constituting monomers, and the interruption of the conjugation of chains on the electrical conductivity process. 
EXPERIMENTAL

Ten polymers have been prepared by using solution polymerization (Gadoge et al., 1989) via the condensation of terephthaloyl dichloride, isophthaloyl dichloride, maleic anhydride, and maleoyl dichloride as diacids with different diols and one type of diamine as follows: (Table 1)

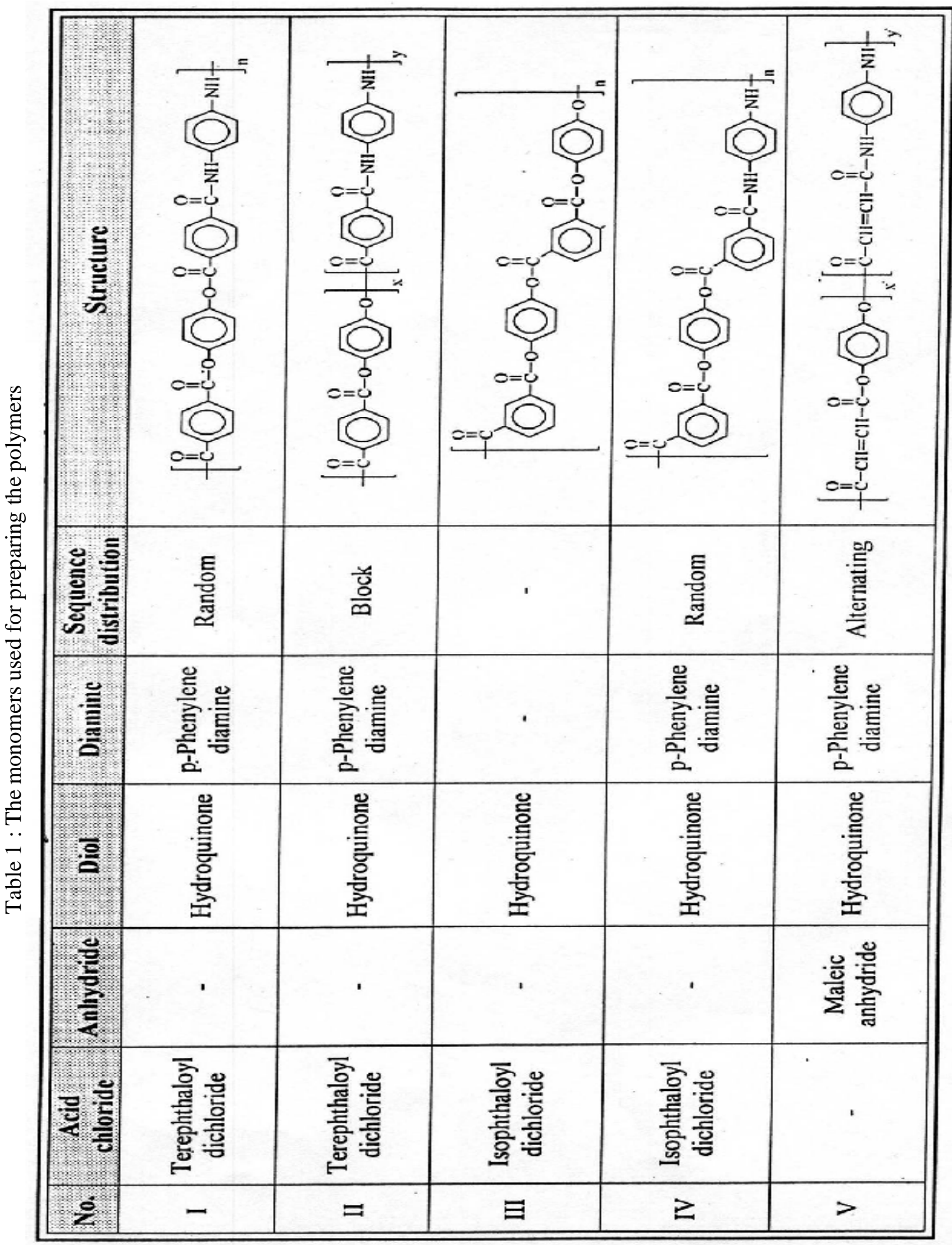




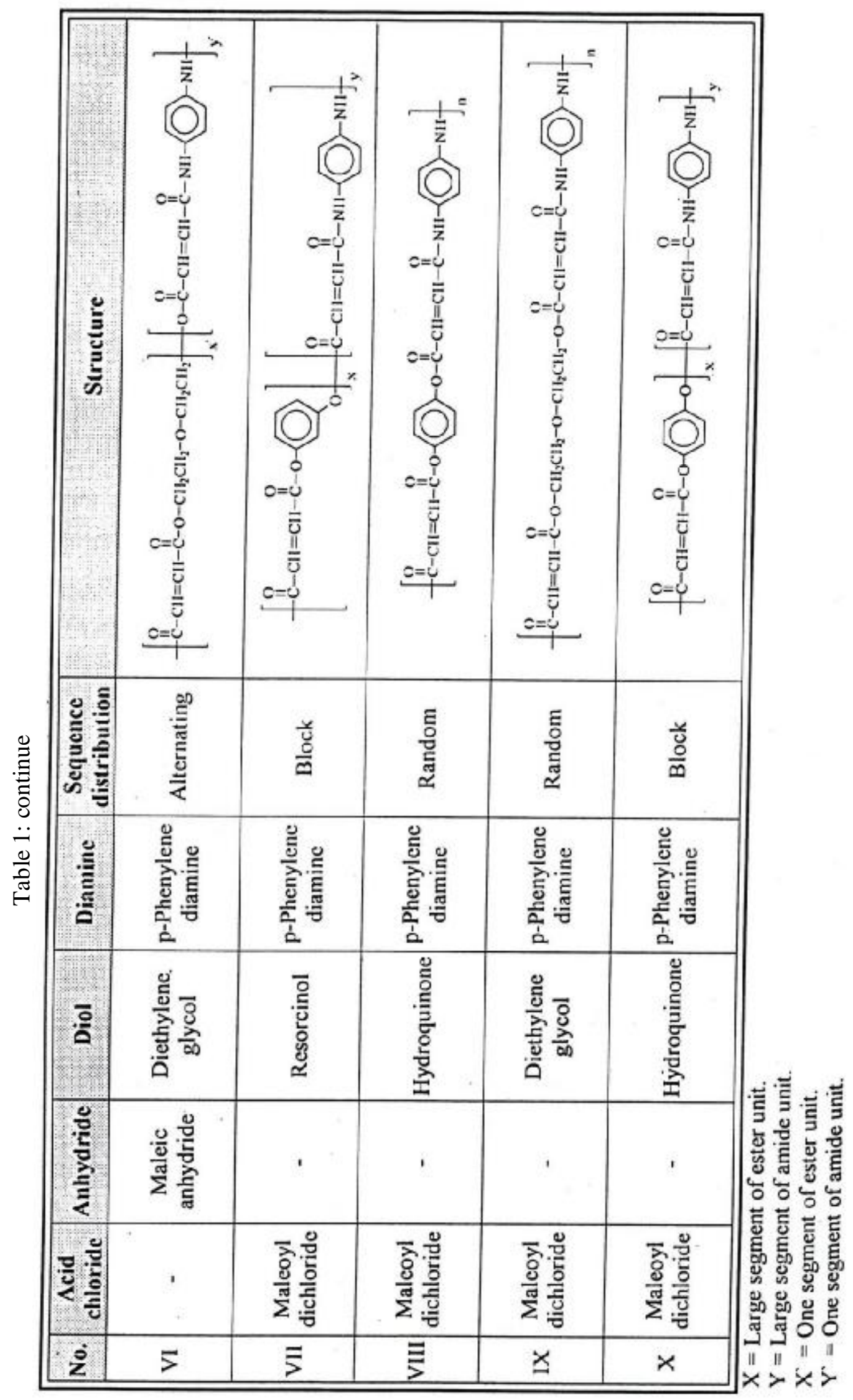


Polymer (I): 0.05 mole of terephthaloyl dichloride were dissolved in $40 \mathrm{ml}$ dry dichloroethane (DCE). A mixture of 0.025 mole of hydroquinone and 0.025 mole of $p$ phenylenediamine in $40 \mathrm{ml}$ of 1:1 DCE: pyridine mixed solvent was added dropwise to the first solution under nitrogen atmosphere. The temperature of the reaction was kept in the range $\left(0-5^{\circ} \mathrm{C}\right)$. The precipitated poly(amide-ester) was poured into excess amount of methanol after 24 hours stirring at room temperature, and then filtered and dried under vacuum.

Polymer (II): 0.0125 mole of hydroquinone dissolved in $10 \mathrm{ml}$ of 1:1 DCE: pyridine mixed solvent was added dropwise to the solution of 0.05 mole of terephthaloyl dichloride in $40 \mathrm{ml}$ dry DCE. The addition period is about 2 hours. 0.0125 mole of $p$-phenylenediamine dissolved in $10 \mathrm{ml} \mathrm{1:1} \mathrm{DCE:} \mathrm{pyridine} \mathrm{mixed} \mathrm{solvent,} \mathrm{was} \mathrm{secondly} \mathrm{added;} \mathrm{the} \mathrm{addition}$ period was about 2 hours. The two step were repeated again. The reaction mixture was stirred for 24 hours at room temperature. The precipitated polymer was further processed as in polymer (I).

Polymer (III): 0.05 mole of hydroquinone was polymerized with 0.05 mole of isophthaloyl dichloride according to the procedure described in the synthesis of polymer (I).

Polymer (IV): isophthaloyl dichloride was polymerized with hydroquinone and $p$ phenylenediamine as in polymer (I).

Polymer (V): 0.02 mole of 1,4-dimaleoyl hydroquinone and 0.02 mole of N,N`-diacetoyl-pphenylene diamine were dissolved in DMF. A stream of nitrogen gas was passed through the mixture for $15 \mathrm{~min}$. the mixture was heated at $100^{\circ} \mathrm{C}$ for $3 \mathrm{hrs}$ and at $130{ }^{\circ} \mathrm{C}$ for $2 \mathrm{hrs}$., then at $160{ }^{\circ} \mathrm{C}$ for additional $2 \mathrm{hrs}$. to remove the acetic acid azeotropically with DMF, which was added dropwise so as to keep its amount constant.

The yellow white precipitated polymer was filtered, and washed with DMF.

Polymer (VI): 0.02 mole of 1,5-diethylene glycol was polymerized with 0.02 mole of N,N`diacetoyl- $p$-phenylene diamine according to the method of preparing polymer $(\mathrm{V})$.

Polymer (VII): maleoyl dichloride was polymerized with resorcinol and $p$-phenylene diamine as in the preparation of polymer (II).

Polymer (VIII): maleoyl dichloride was polymerized with hydroquinone and $p$-phenylene diamine as in the preparation of polymer (I).

Polymer (IX): maleoyl dichloride was polymerized with diethylene glycol and $p$-phenylene diamine as in the preparation of polymer (I).

Polymer (X): maleoyl dichloride was polymerized with hydroquinone and $p$-phenylene diamine as in preparing polymer (II).

The Tg was measured according to the methods suggested by Serin and Co-worker (Serin , 2004 ) 


\section{Infrared spectra of the polymers:}

The FTIR spectra of the investigated polymers show all absorptions expected for the different groups of the polymers. (Table 2)

Table 2: FTIR bands for functional groups of the prepared polymers $\left(\mathrm{cm}^{-1}\right)$.

\begin{tabular}{|c|c|c|c|c|c|c|}
\hline polymer & C=Oester & C=Oamide & C=Caliph. & O-H,N-H & C-O & C-N \\
\hline I & 1730 & 1688 & - & 3427 & 1188 & 1277 \\
\hline II & 1728 & 1647 & - & 1411 & - & - \\
\hline III & 1733 & - & - & 3453 & 1178 & - \\
\hline IV & 1689 & 1633 & 1505 & 3435 & 1170 & 1282 \\
\hline V & 1720 & 1653 & 1630 & 3434 & 1174 & - \\
\hline VI & 1662 & 1668 & 1572 & 3306 & - & 1318 \\
\hline VII & 1663 & 1630 & 1580 & 3439 & - & 1318 \\
\hline VIII & 1706 & 1689 & 1639 & 3387 & 1171 & 1319 \\
\hline IX & - & 1631 & 1613 & 3398 & - & - \\
\hline X & 1700 & 1689 & 1641 & 3421 & 1171 & 1315 \\
\hline
\end{tabular}

\section{Synthesis of polymers:}

\section{RESULTS AND DISCUSSION}

The synthesis of copolymers with different sequence distribution were achieved as follows:

a. In the synthesis of the random copolymers an equi-molar mixture of the diamine and diol were added dropwise to the acid dichloride.

b. In the synthesis of the block copolymers the diamine and diols were added portionwise and sequentially to the acid dichloride .

c. In the synthesis of the alternating copolymers an equimolar mixture of the diamine diacetoyl and diol dimaleoyl were heated together in a solvent, whereby ester exchange between acetic and maleic acids occurred and the liberated acetic acid was removed azeotropically.

\section{The effect of monomer sequence distribution on the Electrical conductivity:}

The amide groups in the copoly(amide-ester) are more efficient in the transmission of conjugation than the ester groups, because of lone-pairs of electrons on the ester oxygen are of lower capability of conjugation with the neighboring $\pi$-electrons than the amide groups(Billmeyer, 1984).This means that the longer sequence of ester group in the chain (the case of block copolymers) will lead to a decreased conjugation along the chains. Thus, it is to be expected that the conjugation efficiency in these kinds of copolymers decreases as going from the alternating, to the random, then to the block structures. Table 3 gives the electrical conductivity of the investigated copolymers both in the pure state and doped with different concentrations of iodine and ferric chloride. The results show that the electrical conductivity of pure polymer (IV) is higher than that of polymer (III); polymer (III) possesses more chain flexibility, but lower conjugation efficiency than polymer (IV), since polymer (III) is a polyester composed of isophthalic acid and hydroquinone, but polymer 
(IV) is a copoly (amide-ester) composed of isopthalic acids, hydroquinone, and $p$-phenylene diamine.

As a matter of fact, the existence of molecular self-association among the chains is another important factor affecting the electrical conductivity of these materials. This association favours the inter-chain electronic transfer (Bake and Yager,1942)

The amide group are capable of forming hydrogen bonds with themselves and with the ester groups. Hence, the chains of polymer (IV) form self associations, while there are no possibility for the formation of such an association among the chains of polymer (III).

In this case we can say that the conjugation and association effects overweigh the flexibility effect. This is also the case with the application of high concentration of Iodine as a dopant, and in the case of low concentration of ferric chloride as a dopant.

The situation is reversed by using intermediate concentration of iodine dopant and high concentration of ferric chloride dopants.

It is worth mentioning that the presence of dopant introduces rigidity in the polymeric matrix(Wegner,1981), and that the mechanism of enhancing conductivity by dopant differs according to the type of polymer -dopant interactions. Iodine is capable of forming complexes with the amide groups(Jada and Nagakura, 1962).Polymer -ferric chloride interaction is between sites of high electron densities of polymers and the unoccupied molecular orbitals of ferric ion.

Polymer (I) and (II) are composed of the same monomer units but they are random (polymer I) and block (polymer II). Table 3 show that the undoped polymer (II) has higher conductivity than polymer (I), whereby the flexibility effect is dominating over the conjugation. Block copolymers of this kind are expected to be more flexible than the random one. Polymer (II) doped with iodine gives lower conductivities than polymer (I) by almost all concentrations of the dopant. The improvement of conductivity of polymer (I) and (II) by using the ferric chloride as a dopant fluctuate with the concentration of the dopant.

Polymers (V), (VIII), and (X) are prepared from the same monomer units. They are alternate, random, and block respectively. The electrical conductivity of the pure polymers (V) and (VIII) is almost equal and about three order of magnitude less than that of polymer (X).It is clear that the dominance of the flexibility effect is appare in this case.

Doping with iodine enhances the electrical conductivity of polymer (V) more than polymers (VIII) and (X). Ferric chloride increases the conductivity of all three polymers almost equally.

\section{The effect of the monomer structure on the polymer conductivity :}

Polymer (I), (IV), and (VIII) are all of random type, and they differ only in the constitution of the acid units, which are terephthalic, isophthalic, and maleic acid respectively. Polymer (I) with exclusive para linkages should be the most rigid among the three polymers, because its chains can assume all trans extended structure and hence liable to crystallization. Polymer (IV) with meta linkage possesses coiled chains structure which does not show a tendency to crystallization. This property imparts elasticity to the polymer. Polymer (VIII) is expected to possess elastic property intermediate between polymer (I) and (IV). Considering the data of table 1 with iodine as a dopant, it is evident that polymer (IV) possesses the highest conductivity among the three polymers at low dopant concentrations; this refers to the dominance of chain mobility effects. The situation, however, changes at 
higher dopant concentrations, whereby polymer (I) becomes the polymer with highest conductivity. In the case of the application of ferric chloride as a dopants table 1, the conductivity of polymer (I) is either almost equal or less than the other two polymers by all dopant concentrations.

\section{The effect of interruption of chains conjugation on the conductivity of polymers:}

The alternating polymers (V) and (VI) differ in the diol units, which are hydroquinone and diethylene glycol respectively. Diethylene glycol is saturated and interrupts the conjugation of the chains of polymer (VI). On the other hand diethylene glycol units is flexible and gives elastic behaviour to the polymer chains.

The data in table 3 reveals that polymer (V) has higher conductivity than polymer (VI), in the pure and doped states, whereby the chain conjugation effect is the important factor.

The same behavior is noticed in the case of polymers (VIII) and (IX), which are of random type and their diol units are hydroquinone and diethylene glycol respectively.

The conductivities of these two polymers vary in non-systematic manner with change of iodine concentration, while in the case of ferric chloride as a dopant are almost equal at low concentration, and the conductivity of polymer (VIII) is higher than that of polymer (IX) at a higher dopant concentration.

\section{Change of conductivity with temperature elevation:}

Table (4) shows the electrical conductivities $(\sigma)$ of polymers (I-X) at different temperatures. The plot of $\ln (\sigma)$ versus the inverse absolute temperature shows two regions. The first region, which covers the temperatures below $\mathrm{Tg}$, is less sensitive to temperature variations, while the second region, which covers the temperature above $\mathrm{Tg}$, exhibits a larger temperature dependence. Figure (1) reveals these observation for polymer I. All other polymers behave similarly. 


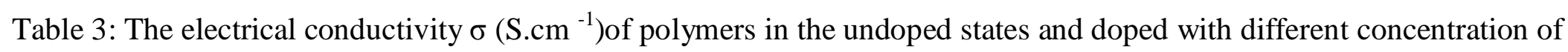
iodine and ferric chloride doping

\begin{tabular}{|c|c|c|c|c|c|c|c|c|c|c|c|}
\hline \multirow[t]{2}{*}{ No. } & \multirow[t]{2}{*}{ Undoped } & \multicolumn{2}{|c|}{$1: 0.1$} & \multicolumn{2}{|c|}{$1: 0.2$} & \multicolumn{2}{|c|}{$1: 0.3$} & \multicolumn{2}{|c|}{$1: 0.4$} & \multicolumn{2}{|c|}{$1: 0.5$} \\
\hline & & $\mathbf{I}_{2}$ & $\mathrm{FeCl}_{3}$ & $\mathbf{I}_{2}$ & $\mathrm{FeCl}_{3}$ & $\mathbf{I}_{2}$ & $\mathrm{FeCl}_{3}$ & $\mathbf{I}_{2}$ & $\mathrm{FeCl}_{3}$ & $\mathbf{I}_{2}$ & $\mathrm{FeCl}_{3}$ \\
\hline I & 4.5347 E-11 & $\begin{array}{c}3.5971 \mathrm{E}- \\
10\end{array}$ & $\begin{array}{c}4.6202 \mathrm{E}- \\
10\end{array}$ & $1.08 \mathrm{E}-8$ & $\begin{array}{l}1.1666 \mathrm{E}- \\
9\end{array}$ & $1.8 \mathrm{E}-8$ & 3.04 E-8 & $1.462 \mathrm{E}-7$ & 3 E-9 & $2.644 \mathrm{E}-7$ & $3.05 \mathrm{E}-8$ \\
\hline II & $\begin{array}{c}4.5957 \mathrm{E}- \\
10\end{array}$ & $\begin{array}{c}1.7350 \mathrm{E}- \\
10\end{array}$ & $\begin{array}{c}9.1446 \mathrm{E}- \\
10\end{array}$ & $1 \mathrm{E}-9$ & $1 \mathrm{E}-9$ & 6.6 E-9 & 9 E-9 & 8.42 E-8 & $1.32 \mathrm{E}-8$ & $4.22 \mathrm{E}-7$ & 9.4 E-8 \\
\hline III & 3.6711 E-11 & $3.2 \mathrm{E}-9$ & $\begin{array}{c}1.5073 \mathrm{E}- \\
10\end{array}$ & $1.32 \mathrm{E}-8$ & $1.8 \mathrm{E}-9$ & $\begin{array}{c}6.36 \mathrm{E}- \\
8\end{array}$ & $4.004 \mathrm{E}-7$ & 9 E-9 & 1.637 E-6 & $1.152 \mathrm{E}-7$ & 8.43 E-7 \\
\hline IV & $\begin{array}{c}1.3691 \mathrm{E}- \\
10\end{array}$ & $1 \mathrm{E}-9$ & $4.4 \mathrm{E}-10$ & $1 \mathrm{E}-9$ & 4.4 E-9 & $1.3 \mathrm{E}-8$ & $4.381 \mathrm{E}-7$ & 1.92 E-8 & $4.496 \mathrm{E}-7$ & $5.10 \mathrm{E}-7$ & 2.14 E-8 \\
\hline $\mathbf{V}$ & $1.5663 \mathrm{E}-11$ & 1 E-9 & $1.5 \mathrm{E}-10$ & $1.18 \mathrm{E}-8$ & $1.34 \mathrm{E}-8$ & $1.69 \mathrm{E}-7$ & $9.2 \mathrm{E}-8$ & $\begin{array}{c}2.3622 \text { E- } \\
6\end{array}$ & $5.516 \mathrm{E}-7$ & 1.234 E-6 & $1.88 \mathrm{E}-8$ \\
\hline VI & 1.1823 E-11 & $1.587 \mathrm{E}-10$ & $\begin{array}{c}6.7169 \mathrm{E}- \\
10\end{array}$ & $1 \mathrm{E}-9$ & $8.5 \mathrm{E}-8$ & $\begin{array}{c}3.74 \text { E- } \\
8\end{array}$ & $1.14 \mathrm{E}-8$ & $3.77 \mathrm{E}-7$ & $1.12 \mathrm{E}-7$ & 3.396 E-6 & 7.8 E-9 \\
\hline VII & 5.1553 E-11 & $\begin{array}{c}1.4475 \mathrm{E}- \\
10\end{array}$ & $\begin{array}{c}1.1224 \text { E- } \\
10\end{array}$ & $1.6 \mathrm{E}-9$ & 3.48 E-8 & $1 \mathrm{E}-8$ & $1.72 \mathrm{E}-7$ & $4.3 \mathrm{E}-8$ & $\begin{array}{l}1.2579 \mathrm{E}- \\
5\end{array}$ & $2.36 \mathrm{E}-8$ & 7.2 E-8 \\
\hline VIII & $1.8716 \mathrm{E}-11$ & $1.3619 \mathrm{E}-10$ & $3.6116 \mathrm{E}-10$ & 1.8 E-9 & $6.2 \mathrm{E}-8$ & $1.8 \mathrm{E}-9$ & $2.312 \mathrm{E}-7$ & $6.2 \mathrm{E}-9$ & $3.672 \mathrm{E}-7$ & $3.3 \mathrm{E}-8$ & $2.536 \mathrm{E}-7$ \\
\hline IX & 1.1813 E-11 & $\begin{array}{c}1.3846 \mathrm{E}- \\
10\end{array}$ & $\begin{array}{c}1.5406 \mathrm{E}- \\
10\end{array}$ & $\begin{array}{c}2.5402 \text { E- } \\
10\end{array}$ & 7.56 E-8 & $1 \mathrm{E}-9$ & $8.2 \mathrm{E}-8$ & $1.4 \mathrm{E}-8$ & $1.476 \mathrm{E}-7$ & $4.8 \mathrm{E}-8$ & $4.76 \mathrm{E}-8$ \\
\hline $\mathbf{X}$ & $3.5 \mathrm{E}-8$ & $\begin{array}{c}8.8964 \text { E- } \\
10\end{array}$ & $\begin{array}{c}8.0866 \text { E- } \\
10\end{array}$ & $1 \mathrm{E}-9$ & $1.2 \mathrm{E}-8$ & 8.2 E-9 & $5.322 \mathrm{E}-8$ & $1.6 \mathrm{E}-8$ & $3.464 \mathrm{E}-7$ & 6.4 E-8 & $1.31 \mathrm{E}-8$ \\
\hline
\end{tabular}


Table 4: The conductivities $\left(\right.$ S.cm $\left.{ }^{-1}\right)$ of polymers (I-X) at different temperatures

\begin{tabular}{|c|c|c|c|c|c|c|c|c|}
\hline Polymer no. & $303 \mathrm{~K}$ & $313 \mathrm{~K}$ & $323 \mathrm{~K}$ & $333 \mathrm{~K}$ & $343 \mathrm{~K}$ & $353 \mathrm{~K}$ & $363 \mathrm{~K}$ & $373 \mathrm{~K}$ \\
\hline I & $3.01 \mathrm{E}-11$ & $3.28 \mathrm{E}-11$ & 3.97 E-11 & $4.43 \mathrm{E}-11$ & $4.77 \mathrm{E}-11$ & $5.54 \mathrm{E}-11$ & $8.38 \mathrm{E}-11$ & $1.5 \mathrm{E}-10$ \\
\hline II & 5.67 E-11 & $6.72 \mathrm{E}-11$ & 9.86 E-11 & $1.21 \mathrm{E}-10$ & $3.11 \mathrm{E}-10$ & $6.03 \mathrm{E}-10$ & $6.86 \mathrm{E}-10$ & 1.00 E-9 \\
\hline III & 3.14 E-10 & $3.49 \mathrm{E}-10$ & $4.10 \mathrm{E}-10$ & 5.24 E-10 & $6.28 \mathrm{E}-10$ & 8.57 E-10 & $9.43 \mathrm{E}-10$ & 1.00 E-9 \\
\hline IV & $4.52 \mathrm{E}-11$ & 5.47 E-11 & $6.86 \mathrm{E}-11$ & 8.49 E-11 & $1.13 \mathrm{E}-10$ & $2.09 \mathrm{E}-10$ & 6.17 E-10 & 1.00 E-9 \\
\hline $\mathrm{V}$ & 7.86 E-12 & 8.00 E-12 & $1.26 \mathrm{E}-11$ & $1.43 \mathrm{E}-11$ & $1.29 \mathrm{E}-11$ & $1.2 \mathrm{E}-11$ & $1.42 \mathrm{E}-11$ & $1.55 \mathrm{E}-11$ \\
\hline VI & $1.31 \mathrm{E}-11$ & $1.58 \mathrm{E}-11$ & $1.62 \mathrm{E}-11$ & 1.77 E-11 & $1.81 \mathrm{E}-11$ & $1.88 \mathrm{E}-11$ & $2.06 \mathrm{E}-11$ & $2.39 \mathrm{E}-11$ \\
\hline VII & $8.62 \mathrm{E}-11$ & $1.31 \mathrm{E}-10$ & $1.49 \mathrm{E}-10$ & 1.97 E-10 & $1.22 \mathrm{E}-10$ & $1.53 \mathrm{E}-10$ & $1.49 \mathrm{E}-10$ & $4.00 \mathrm{E}-10$ \\
\hline VIII & 2.13 E-11 & 2.33 E-11 & $2.62 \mathrm{E}-11$ & $2.78 \mathrm{E}-11$ & 3.95 E-11 & 4.97 E-11 & $6.5 \mathrm{E}-11$ & $6.89 \mathrm{E}-11$ \\
\hline IX & $1.2 \mathrm{E}-11$ & $1.25 \mathrm{E}-11$ & $1.61 \mathrm{E}-11$ & 1.73 E-11 & 1.94 E-11 & $2.03 \mathrm{E}-11$ & $2.53 \mathrm{E}-11$ & $3.12 \mathrm{E}-11$ \\
\hline$X$ & $9.8 \mathrm{E}-8$ & $1.17 \mathrm{E}-7$ & $1.92 \mathrm{E}-7$ & $3.27 \mathrm{E}-7$ & $6.48 \mathrm{E}-7$ & $4.15 \mathrm{E}-6$ & $2.07 \mathrm{E}-5$ & $2.07 \mathrm{E}-5$ \\
\hline
\end{tabular}




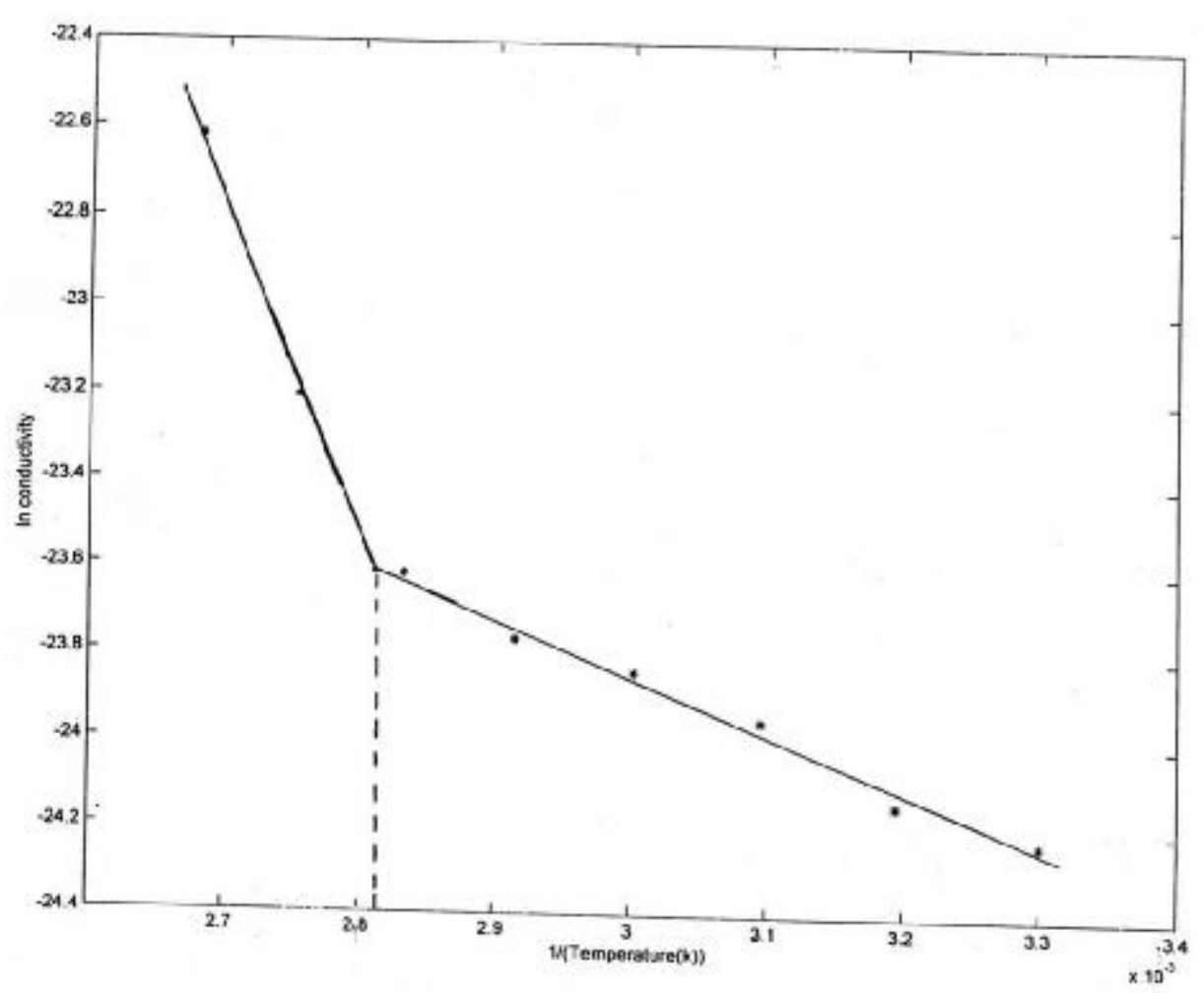

Fig.1: Relationship between in(conductivity) and the inverse absolute temperature for polymer (I)

The activation energies for the temperature dependence of conductivity of different polyazomethines determind by shahb and Co-workers(AL-Shawabkeh, 2007), lie in the range (0.1-0.49) eV.mol ${ }^{-1}$. M. Serin and Co-workers attributed the increase of conductivity with the elevation of temperature to the rise in population of electrons in the exited state (conduction band) (Serin et al., 2004). This excitation involves the transfer of electrons from the HOMO to the LUMO of the organic semiconductor for coloured compounds, which is the case for conjugated polymers. The excitation energy lies in the range of (1.5-2) eV.mol ${ }^{-1}$, therefore, Shahab and co-workers explained this behavior in terms of the increase of the mobility of chain segments with the increase in the temperature.

Below $\mathrm{Tg}$, large-scale segmental motion of polymeric chains does not take place, only few types of restricted motions exist below this temperature. In these types of motions the moving moieties (side-chains, phenylene or methylene groups in the main chain) do not change place, but rathor or carry torsional motions around an equilbrium position. In this case the charge with the necessity to overcome high energy barriers due to the existence of electric fields.

Above $\mathrm{Tg}$, a liquid like motion of long segments of the polymeric chains becomes possible which gives rise to inter-chain collosions, and enables the electron to jump from one chain to another.

Some of the polymers containing maleic anhydride units $(\mathrm{V}-\mathrm{X})$ show irregularity in the temperature-conductivity dependece curve near the $\mathrm{Tg}$. This behaviour is due to the isomerization of maleic to fumaric units with a change of the position of the $\mathrm{Tg}$. 
The population of electrons from HOMO to LUMO by increasing temperature is very limited in this case due to the high energy gap separating these energy levels. Therefore the contribution of the electronic excitation to the increase of conductivity due to temperature elevation is minor compared with the contribution arising from the increase in the mobility of chains.

The activation energies determined in this work for the invistigated polymers (table 5) lie in the range (0.11-0.74) eV.mol ${ }^{-1}$ which is very close to those obtained by shahab and coworkers for conjugated polyazomethines. Hence, we think that the increase in chains segmental mobility at elevated temperature is also in this case responsible for the conductivity enhancement.

Table 5: The activation energies of the electrical conductivity of polymers (1-X) before and after transition temperature $\left(\mathrm{Ea}_{1}\right)$ and $\left(\mathrm{Ea}_{2}\right)$

\begin{tabular}{|c|c|c|}
\hline Polymer & $\mathbf{E a}_{\mathbf{1}} / \mathbf{e V} \cdot \mathbf{m o l}^{\mathbf{1}}$ & $\mathbf{E a}_{\mathbf{2}} / \mathbf{e V} \cdot \mathbf{m o l} \mathbf{~}^{\mathbf{1}}$ \\
\hline I & 0.11 & 0.33 \\
\hline II & 0.21 & 0.33 \\
\hline III & 0.25 & 0.066 \\
\hline IV & 0.19 & 0.67 \\
\hline V & 0.17 & 0.11 \\
\hline VI & 0.05 & 0.12 \\
\hline VII & 0.23 & 0.34 \\
\hline VIII & 0.07 & 0.29 \\
\hline IX & 0.091 & 0.12 \\
\hline X & 0.74 & 0.69 \\
\hline
\end{tabular}

\section{Effect of the structure of polymer on $\mathrm{Tg}$ :}

There are many factors which influence the Tg of the polymers. The most important of these factors are the nature of monomers constituting the polymers and their sequence distribution (Billmeyer, 1984) However the existence of strong hydrogen bonding in the investigated copolymers leads to certain irregularities and unexpected results.

Table (6) gives the Tg of the studied polymers. Tg of polymers I, IV and VIII decrease from 354 to 344 to $333 \mathrm{~K}$ as the acidic units change form terephthalic to isophthalic to maleic. 
Table 6: The glass transition temperature of polymers (I-X)

\begin{tabular}{|c|c|}
\hline Polymer & Tg $(\mathbf{K})$ \\
\hline I & 354 \\
\hline II & 337 \\
\hline III & 347 \\
\hline IV & 344 \\
\hline V & 353 \\
\hline VI & 358 \\
\hline VII & 342 \\
\hline VIII & 333 \\
\hline IX & 357 \\
\hline X & 347 \\
\hline
\end{tabular}

The aromatic groups introduce stiffness in the polymeric chains(Allkock et al.,2003), with a larger effect of the para terephthalic acid compared with meta isophthalic acid, since the former can give trans extended structure of polymeric chains, that possess great tendency to crystallization

Polymers V, VIII and X are all composed of the same monomeric units, but they differ in the sequence distribution. They are alternate, random and block respectively. The $\mathrm{Tg}$ for these polymers have the order:

$$
\mathrm{V}>\mathrm{X}>\mathrm{VIII}
$$

This can be rationalized in terms of the regularity and associated tendency to crystallization of the chains which is largest with polymer V and smallest with polymer X. these results indicate that the sequence distribution of the monomers in the chains strongly effect the Tg and in the order:

Alternate $>$ random $>$ block

This behaviour was noticed clearly with polymers I and II, which are composed of other monomer units.

The values of the Tg of polymers VIII and IX are also unexpected; They are both random and different only in the diol units. Contrary to expectation, the replacement of hydroquinone with diethylene glycol raised the Tg instead of lowering it. Diethylene glycol is an aliphatic ether. Ethers are known to be very flexible due to the ease of rotation around the ether linkage. Apparently, the rotation is restricted in this case because of the involvement of the ether linkage with hydrogen bonding. 


\section{REFERENCES}

Allkock, H.R.; Lampe, F.W. ; Mark J.E. (2003). "Contomparary Polymer Chemistry", 3rd edn., Pearson Education, Inc., 962 p.

AL-Shawabkeh, A. F.; AL-Wahab, H. A. ; Shihab, Y. A. (2007). Temperature dependence of the electrical conductivity of some conjugated polyazomethine, J. Optoelectron. Adv.Mat.,9(7), 2075.

Bake, W.O. ; Yager, W.A. (1942). The relation of dielectric properties to structure crystalline polymers .II Linear polyamides, J. Am. Chem. Soc.,64,2171.

Billmeyer, F.W.JR. (1984)."Text Book of Polymer Science", 3rd edn., Johen-Willy and sons. 515 p.

Blythe, A. R. (1979). "Electrical Properties of Polymers", Cambridge University press, $90 \mathrm{p}$.

Gadoge, R. S.; Paurathnam, S. ; Nadkarni, V. B. (1989). Thermotropic mesomorphic polyesters. I copolyesters of terephthalic acid, hydroquionone and flexible diols ., $J$. Appl. polym. Sci., 37,1579.

Jada, H.; Tanaka, J. ; Nagakura, S. (1962). Infrared absorption spectrum of charge transfer complex between trimethylamine and iodine, J. Mol. Spectrosc. 9,461.

Keith, Y. (1978). "Hukel Molecular Orbital Theory", Academic press, Inc., New York. 782 p.

Serin, M.; Sukar, D.; Kanlcurtaran, O. ; Karaman, Y.F. (2004). Electrical properties of the copolyesters of bisphenol A with terephthalic acid, J. Optoelectron. Adv. Mat. 6 (1), 283.

Wegner, G. (1981). Polymers with metal-like conductivity -a review of their synthesis , structure and properties. Angew. Chem. Int. Ed. Eng., 20,361.

Yang, Z.; Karaz, F. E.; Giese, H.J. (1994). Synthesis of conducting polymer with short alternating conjugated block. Polymer, 35, 391. 